\title{
COMMENTARY
}

\section{Tracheostomy patients on the ward: multiple benefits from a multidisciplinary team?}

\author{
Mihae $\mathrm{Yu}^{*}$ \\ See related research by Garrubba et al., http://ccforum.com/content/13/6/R177
}

\begin{abstract}
Patients requiring tracheostomies tend to have a longer length of stay due to their underlying disease. After a thorough literature search, Garrubba and colleagues found only three studies assessing the impact of multidisciplinary teams (MDTs) on tracheostomy patients on the ward. One consistent observation was the decreased time to decannulation after institution of MDT care when compared with historical controls. Although a large prospective randomized trial is desirable before MDT is recommended, many institutions may have already formed a team approach to provide coordinated care resulting in improved outcome and length of stay.
\end{abstract}

Tracheostomy is one of the most frequent procedures done in an intensive care unit (ICU). More than 100,000 tracheostomies are performed annually in the US (Healthcare Cost and Utilization Project 2007). The reason for tracheostomies may be diverse, but the patients tend to have a long length of stay. Due to large differences between hospital resource consumption and reimbursement, the Health Care Financing Administration added new diagnosis-related groups in 1987, with heavy weights given to tracheostomy patients. Surprisingly, there is a paucity of studies addressing the multifaceted care of these difficult patients to minimize length of stay and complications once the patient leaves the ICU.

As reported in the previous issue of Critical Care, Garrubba and colleagues [1] culled the literature and

\footnotetext{
*Correspondence: mihaey@hawaii.edu

'Department of Surgery, Division of Surgical Critical Care, Queen's Medical Center, University of Hawaii, 1356 Lusitana Street, 6th floor, Honolulu, HI 96813, USA
}

found only three studies [2-4] assessing the impact of a multidisciplinary team (MDT) on outcome of tracheostomy patients on the ward. All studies compared results with historical controls, and despite the problems intrinsic in cohort studies, the consistent observation was decreased time to decannulation [2-4], and two of the three studies revealed decreased length of stay [3,4]. Specific outcomes and complications pertinent to tracheostomy patients were notably absent in these studies, although the implication is improved patient care. One study [2] reported improvement in nursing compliance of tracheostomy care plan after institution of MDT, and death and code blues were less common (albeit not statistically significant) in the other two studies [3,4].

In regard to tracheostomy patients, there are multiple variables that may impact clinical outcome, complications, or length of stay or all three. Some of these considerations are the following:

1. Early versus late timing of tracheostomy [5]

2. The surgical technique itself: percutaneous versus open surgery

3. Choice of size and type of tube: double versus single cannula and size of tube in relation to the patient to provide the best function with least airway injury

4. The best practical method to assess swallowing and prevent aspiration

5. The optimum steps leading to safe decannulation

6. Methods of tracheostomy handling to prevent pulmonary infection

7. Provision of pulse oximetry monitoring for higherrisk patients in a stepdown unit

8. Preventive measures to avoid tube obstruction such as hydration, humidification of airway, and suctioning of secretions

9. Factors leading to inadvertent decannulation (such as underlying mental status) and the best way of securing tracheostomy tubes (suturing versus tie)

10. Psychosocial well-being of patients with earlier speech therapy and effective swallowing leading to better communication, less isolation, and improved nutritional support 
11. Availability of ethics team for end-of-life issues for futile care.

It will be difficult to control for all of these factors.

Another question raised was whether the makeup of the MDT makes a difference [1]. The background of the physician may not be as important as their interest in these patients and the participation of the respiratory therapist, speech pathologist, clinical nurse specialist, physiotherapist, and dietitian. Tobin and Santamaria [3] reorganized the existing staff to provide coordinated care without additional costs. Resource expenditure on more personnel during times of health care cost crisis may be offset by the decreased length of stay and avoidance of catastrophic events. This lesson may be learned from other specialties in which utilization of case managers for a specific group of patients (such as trauma victims) may lead to decreased hospital days and improved care [6] and is currently the standard of practice in trauma centers.

Other articles report favorably on the concept of MDT [7-10]. It is probable that many institutions already have a modification of the MDT or a stepdown unit prompted by some catastrophic event of tracheostomy patients or both. A philosophical question is whether we can ethically design a prospective randomized trial in which the control group does not receive the benefits of multidisciplinary care. The concept of MDT may be a common sense issue in which patient benefits and decreased length of stay occur due to small increments of coordinated efforts without a large-scale prospective randomized trial to 'prove' that MDT works. Recent studies advocate earlier performance of tracheostomies to decrease ICU length of stay [5], and the number of tracheostomies performed may increase in the future, making this topic even more important. Garrubba and colleagues have given us fuel for thought.
Abbreviations

$\mathrm{ICU}=$ intensive care unit; $\mathrm{MDT}=$ multidisciplinary team.

\section{Competing interests}

The author declares that they have no competing interests.

Published: 29 January 2010

\section{References}

1. Garrubba M, Turner T, Grieveson C: Multidisciplianry care for tracheostomy patients: a systematic review. Crit Care 2009, 13:R177.

2. Arora A, Hettige R, Efeacho R, Narula A: Driving standards in tracheostomy care: a preliminary communication of the St Mary's ENT-led multidisciplinary team approach. Clin Otolaryngol 2008, 33:596-599.

3. Tobin AE, Santamaria JD: An intensivist-led trachesotomy review team is associated with shorter decannulation time and length of stay: a prospective cohort study. Crit Care 2008, 12:R48.

4. Cameron TS, McKinstry A, Burt SK, Howard ME, Bellomo R, Brown DJ, Ross JM, Sweeney JM, O'Donoghue FJ: Outcomes of patients with spinal cord injury before and after introduction of an interdisciplinary tracheostomy team. Crit Care Resusc 2009, 11:14-19

5. Griffiths J, Barber VS, Morgan L, Young JD: Systematic review and metaanalysis of studies of the timing of tracheostomy in adult patients undergoing artificial ventilation. BMJ 2005, 330:1243-1247.

6. Curtis K, Zou Y, Black D: Trauma care management: improving patient outcomes. Injury 2006, 37:626-632.

7. Frank U, Mader M, Sticher H: Dysphagic patients with tracheostomies: a multidisciplinary approach to treatment and decannulation management. Dysphagia 2007, 22:20-29

8. Norwood MG, Spiers P, Bailiss J, Sayers RD: Evaluation of the role of a specialist tracheostomy service. From Critical Care to outreach and beyond. Postgrad Med J 2004, 80:478-480.

9. Hunt K, McGowan S: Tracheostomy management in the neurosciences: a systemic, multidisciplinary approach. Br J Neuroscience Nursing 2005, 1:122-125.

10. Parker V, Archer W, Shylan G, McMullen P, Smith K, Giles M: Trends and challenges in the management of tracheostomy in older people: the need for a multidisciplinary team approach. Contemp Nurse 2007, 26:177-183.

doi:10.1186/cc8218

Cite this article as: Yu M: Tracheostomy patients on the ward: multiple benefits from a multidisciplinary team? Critical Care 2010, 14:109. 